\title{
"Why do we not buy mass customised products?" - An investigation of consumer purchase intention of mass customised products
}

\author{
Huiwen Zhao \\ Lecturer, Bournemouth University, Fern Barrow, Poole, BH12 5BB, United Kingdom, \\ hzhao@bournemouth.ac.uk \\ Leigh McLoughlin \\ Senior Lecturer, Bournemouth University, Fern Barrow, Poole, BH12 5BB, United Kingdom, \\ Imcloughlin@bournemouth.ac.uk \\ Valery Adzhiev \\ Principal Academic, Bournemouth University, Fern Barrow, Poole, BH12 5BB, United Kingdom, \\ vadzhiev@bournemouth.ac.uk \\ Alexander Pasko \\ Professor, Skolkovo Institute of Science and Technology, Ulitsa Nobelya, 3, Moskva, Moscow Oblast, 121205, \\ Russia; \\ Professor, Bournemouth University, Fern Barrow, Poole, BH12 5BB, United Kingdom, \\ apasko@bournemouth.ac.uk
}

Received (3.12.2018.); Revised (5.04.2019); Accepted (9.04.2019.)

\begin{abstract}
Mass customisation has become a prospective business strategy for many industries. Despite the great efforts that have been put into implementing product configuration systems (e.g., NikelD), the Deloitte Consumer Review 2019 indicated that nearly half of consumers still prefer to buy mass produced products. Another study by Khan and Haasis (2016) also concluded that the increase in mass customisation has led to a decline in customer satisfaction of the sales process. Given these considerations, this paper aims to investigate, from the consumer's perspective, the factors that influence consumer purchase intention of online mass customised products. The primary contribution of this study is that we found in addition to price and design freedom, website information quality and the visual presentation of customisable products have significant influences on consumer purchase intention. Specifically, participants preferred to have intuitive and sufficient information as well as a 3D visualisation of the products to help them understand what the customisation options are, how to interact with them and to see a full view of the final products. In addition, we found participants responded differently to new companies and well-established companies. Here, lack of trust is one of the main reasons stopping consumers from purchasing mass customised products from new companies; while for well established companies consumer individual differences especially their personal preference is more determinant. Accordingly, we suggest that new startup companies and well-established companies should take different strategies to attract potential consumers.
\end{abstract}

Key words: Consumer experience, Mass customisation, Purchase intention, Success factors

\section{INTRODUCTION}

Mass customisation has grown as a prospective business strategy for many industries over the last few decades. The term "mass customisation" was introduced by Davis in 1987 and was considered to be a new approach to business where companies attempt to offer unique products and services to customers [26]. Davis emphasised the paradox of mass customisation it 'is understood to be both part (customised) and whole (mass) simultaneously' [27]. In other words, mass customisation on the one hand attempts to satisfy the specific needs and desires of individual customers; while on the other hand it is supposed to provide products and services for a relatively large market. Pine [28] further developed the concept and considered it as "a synthesis" of mass production and customisation, i.e. "the mass production of individually customised goods and services". Despite having various definitions, the concept of mass customisation is centred on "producing goods and services to meet individual customer's needs with near mass production efficiency" [29].

Technological developments now make mass customisation a practical possibility. Powerful 
computers, high-speed Internet and sophisticated web browsers enable online customisation of products. Websites therefore become the primary means to turn mass customisation into business practice, which leads to the popularity of online mass customisation. A large amount of effort has been put into creating such online mass customisation websites. On the one hand, companies like Nike, Ford and Dell have set successful examples for the traditional manufacturing industry to embrace the mass customisation era. According to Forbes, Nike has been able to raise their mass customisation sales from $22 \%$ of total sales to $30 \%$ in 2015 , growing their overall margin by $1.4 \%$ year on year[ii]. On the other hand, new start-up mass customisation companies are dedicated to providing personalised products and service, for example, Snapfish (https://www.snapfish.co.uk/home) and Zazzle (https://www.zazzle.co.uk/). To seize the business opportunities, e-commerce company Amazon also launched Amazon Custom (https://services.amazon.co.uk/amazoncustom.html) to encourage companies and merchants to offer customisable products or services on their website.

Despite the great efforts that have been put into turning the concept of mass customisation into practice, the reality is not always optimistic. Compared to the success of employing mass customisation in a traditional manufacturing industry, new start-up companies suffer from a $20 \%$ failure rate, which means 1 in 5 companies could not establish themselves well enough on the market to become a long-term success [15]. Even for the traditional manufacturing companies, their profit from mass customisation has not taken a big portion compared to their mass production sales. For example, although NikeID sets a successful example, mass customisation only represents $20 \%$ of sales in Nike's annual profit, which still has a lot more room for growth ${ }^{[i i]}$. More importantly, the majority of consumers seem to have never purchased any mass customised products. According to research performed by the business advisory firm Deloitte, $36 \%$ of consumers say they are interested in personalised products or services $^{[i v]}$. However, this desire contrasts with a relatively low take up, only one in six of consumers have ever bought customised products or services ${ }^{[v]}$.

The discrepancy between the passionate attempts from industry and the 'wait and see' attitude from consumers leads to a research need: why do consumers not buy mass customised products? In other words, what factors influence consumer decisions to buy mass customised products? Although mass customisation has attracted significant research interest in recent decade, most research efforts focus on identifying and classifying the most efficient and effective ways in which mass customisation can be implemented [1]. Relatively little research has investigated consumer needs and desires towards mass customisation, while even fewer studies provide empirical evidence from the consumer perspective to support their investigation. Research on e-commerce has indicated that the consumer experience is significant to consumer trust, loyalty and repurchases intention [11]. Hart [9] suggested that the most important factor determining success for mass customisation is "customer customisation sensitivity" which considered the uniqueness of consumer needs and the sacrifice gap between the desired product and the products available in the market.

Given these considerations, this paper aims to investigate the factors that influence consumer purchase intention of online mass customisation. The focus is particularly on young consumers aged from 16 to 35. According to Eurostat Statistics ${ }^{[v i]}$, consumers aged 16-44 were the dominant e-shoppers, especially young consumers aged 16-24 who had the highest proportion of e-shoppers purchasing clothes and sport goods $(71 \%)$. Meanwhile, internet users with a higher level of education are more likely to spend their money online. As for mass customisation, those under 40 are more interested, with $43 \%$ of $16-24$ year olds and $46 \%$ 25-30 years olds attracted to personalised products and services ${ }^{[v i i]}$. Therefore, understanding the highlyeducated young consumer's attitude towards mass customisation, especially the factors that influence their purchase intention, will help to discover the 'holy grail' for the success of mass customisation.

In order to gain a deep understanding of consumer needs and desire towards mass customisation, this paper takes an exploratory approach. Participants were invited to customise a product using one of the selected websites and one-to-one interviews were conducted afterwards. Based on the interview results, factors that influence consumer purchase intention have been summarised.

\section{LITERATURE REVIEW}

As a strategy applicable to many businesses, mass customisation attempts to provide personalised service and products to meet each consumer's needs and desires. This has been considered as the key significance of mass customisation [16]. In order to achieve mass customisation, consumers take part in the design process which used to be seen entirely as within the domain of companies and manufacturers [17]. A number of pieces of research have confirmed the positive influence of consumer active participation on their purchase intention of mass customised products. Simonson [4] believed that compared to website automatically personalise offers for consumers, allowing consumers to design the product themselves is important for mass customisation to be successful. Franke et al. [7] confirmed that taking part in the design process led to a positive value increment and increased consumer willingness to pay. Further studies [6] [30] [31] [32] identified that two benefits can be derived from the experience of customising a product: creativeachievement benefit and hedonic benefit. In addition, another three benefits, utilitarian benefit, uniqueness benefit and self-expressiveness benefits are derived from the possession of a customised product. These benefits help consumers feel the pride of authorship and its intrinsic reward.

Existing studies also identified various approaches for consumers to customise a product. A number of studies 
agreed that an attribute-based customisation approach, which allows consumers to decide their preferred level for each attribute of the product, can increase consumer perceived usefulness, enjoyment and satisfaction and lead to a higher probability of purchase. This is in comparison to the alternative-based customisation approach, which allows consumers to make a choice among a set of fully specified product alternatives [2224]. Hermans [25] further considered the way that a product can be customised and categorised four different mechanisms for customisation: (1) Veneer, which allows consumers to customise products by adding a visual decorative layer to a product; (2) Modularity, where products are decomposed into a set of discrete modules and options for their assembly into a customised design; (3) Parametric, which allows consumers to customise a product by changing specific parametric values; and (4) Generative, which creates $2 D$ or $3 D$ forms based on a built-in generation procedure.

Although inviting consumers to join the design process has been considered vital to meet individual needs and desires, consumers may not have a well-defined preference or they may not know what they actually want at the beginning of the design process, and sometimes even if they know what they want, it is difficult for them to describe [13]. Simonson [4] suggested two dimensions of consumer preference to segment consumers into four groups. The two dimensions are the degree to which consumers have stable, well-developed preferences and the consumers' self-insight into those preferences. He also claimed that the majority of consumers have poorly developed and unstable preferences and they tend to have limited insight into their own preferences as well. Given these considerations, the need to fit with consumer preference or being sufficiently attractive are two key factors for consumers to purchase the customised offers. In particular, the more options presented to consumers the more likely they will find the product attractive to them and purchase it [4]. That is because consumers tend to rely on comparisons to assess the value of products. This finding was also indicated by an early study in which consumers were disappointed with the limited choices that mass customisation websites offered at that time [18]. More recent studies confirmed that the majority of consumers would like to have a larger variety of choices and to also play a more active role in the design of the products [19]. Franke et al. [7] also found that providing consumers with higher design freedom generates higher willingness to pay.

However, not all studies agree with the "more are better" effect for deciding the number of options presented to consumers. Consumers have been found be overwhelmed by the number of choices provided by manufacturers, which may lead to 'mass confusion'. This is because excessive choices result in information overload [20]. Since consumers sometimes lack the ability to process overloaded information, they feel confused and annoyed when they are offered too many choices [20]. As a result, this negatively influences consumer enjoyment of customisation and the satisfaction in producing the final product [21]. Huffman and Kahn [22] found that the relationship between consumer satisfaction and the number of choices can be demonstrated in an inverted U-shaped fashion, i.e. after reaching a certain point, the more choices provided, the less satisfied consumers are. Another proposed approach to this problem is to convert the number of choices into the number of products in a bricks-and-mortar store to get an adequate understanding of how many choices the customer should have [20].

In addition to meeting individual consumer needs and desires, another key aspect of mass customisation is it is intended to offer customised products or services at a near mass production price. However, due to the early development of mass customisation and the limitations of manufacturing technologies, most customised products are more expensive than mass produced products [1]. This has been identified as the main inconvenience of mass customisation [1]. Nevertheless, a number of studies have confirmed that consumers are willing to pay a price premium for customised products [5]. According to Forrester research, $81 \%$ of people are willing to pay more for customised products [10]. In this case, mass customisation can help increase a company's profitability by lowing consumers' price sensitivity [3]. Since price is an important criterion for value judgment, the price premium should be in line with the additional value created [5]. Bardakci and Whitelock [1] found in their user studies that customers were willing to pay up to $£ 1,400$ or approximately $10-15$ percent more than mass produced product prices. When considering cultural influences, the price premium that consumers are willing to pay is more complicated. Moon et al. [2] found that consumers in individualistic countries tend to respond to the products more favourably than consumers in collectivistic countries when the personalised products cost the same as standard products or a moderate price premium of up to $15 \%$. However, their response deteriorates considerably and their purchase intention is lower than that of collectivistic consumers when companies charge up to a $30 \%$ premium. Interestingly, collectivistic consumers' purchase intention does not decrease even at this price level. They tend to tolerate a higher price more in order to obtain customised benefits. A few studies have attributed consumer willingness to pay for the price premium to whether or not they can gain a positive emotional experience through the design process and whether or not mass customisation can offer a value increment. [6][7]

In recent years, research interest has been attracted to the importance of website design in the success of mass customisation. As the primary communication tool between consumers and manufacturers, a website transfers the design capability from manufacturers to consumers. Furthermore, it triggers positive emotional responses and promotes consumer willingness to pay [6]. Therefore, website design has been considered as a key success factor in implementing a mass customisation strategy. Franke and Piller [20] proposed three main components of a mass customisation website: core configuration software which provides 
design options and guides consumers through the configuration process; a feedback tool which gives feedback information and visualises design variants; and analysing tools, translating consumer designs into construction plans. Von Hippel [13] suggested that an effective website for user innovation should meet five important objectives: learning by doing via trial-anderror; providing an appropriate "solution space"; being "user-friendly"; offering module libraries and a producible "language" to translate user designs for production. Trentin et al. [12] proposed five capabilities to support consumers to make the decision that best fits their needs, including focused navigation capability, benefit-cost communication capability, flexible navigation capability, easy comparison capability, userfriendly product-space description capability. Sandrin et al. [30] [31] concluded that a mass customisation website with these five capabilities had synergic effects on the three consumer-perceived benefits of mass customised products: utilitarian benefit, uniqueness benefit and self-expressiveness benefit. Zhao et al. [14] also proposed an evaluation model to assess if a $3 D$ mass customisation website can create a satisfying consumer experience by addressing four aspects: individual differences, solution space, interaction design and enabling technologies.

\section{METHODOLOGY}

\subsection{Research question}

As discussed in previous sections, the main research question of this paper is "what are the factors that influence customer decisions to buy mass customised products?"

In order to find answers to this question, an exploratory approach is taken, and the procedure is designed to investigate the research question from the consumer's perspective.

\subsection{Procedure}

The purpose of the user study is to explore factors that influence consumer online purchase intention of customised products. One-to-one semi-structured interviews were conducted in order to gain an in-depth understanding of consumer experience of shopping on mass customisation websites, leading to the discussion of their purchase intention.

Due to the consideration that mass customisation is not a popular online shopping form yet and not everybody has visited or purchased a product on mass customisation websites, we invited participants to design a product using one of the mass customisation websites we selected before the interview. The user study included three stages. In the first stage, participants were invited to customise a product using one of the online mass customisation websites. After this was completed, an interview was conducted in the second stage. Questions started from learning about consumer experience of customising the product, for example, 'Can you tell me what you have done to produce the final product?' 'Tell me about your experience of using this website?' and 'Was there a moment when you felt satisfied or dissatisfied with using the website to customise the product?'. After that, questions focused on investigating consumer purchase intention of the customised product, such as 'Did the final product meet your expectation?' 'Would you buy the final product and why?' In the final stage, the participant filled in a demographic questionnaire. Questions were designed to gather information about consumer gender, age, education, previous online shopping experience and online mass customisation experience.

\subsection{Stimulus}

Two mass customisation websites were selected for the user study: Adidas customize (Fig 1.) and Nervous System (Fig 2.). The reason for selecting these two websites was due to two considerations: first, they represent different approaches to mass customisation website design as reviewed in the previous section. Different approaches may result in different user experiences and purchase intention. Second, they represent successful cases of mass customisation from traditional manufacturing companies and new start-up companies, and they both are in the fashion industry.

Adidas customize employs both alternative-based and attribute-based approaches. It is provided by footwear manufacturing company Adidas, and has set a successful business example for the traditional manufacturing industry to embrace the mass customisation era. Nervous System is a design studio which applies computer simulation to generate designs and digital fabrications. In addition to selling professionally designed artefacts on its website, Nervous System also employs an attribute-based approach for customising products by using their online apps. The product selected for participants to customise was a jewellery piece, which could be designed as either a ring or a bangle.

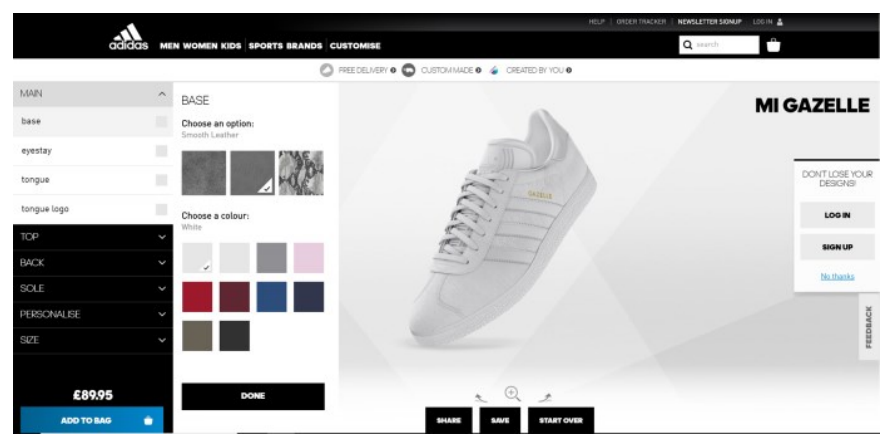

Figure 1. Screenshot of Adidas customize webpage

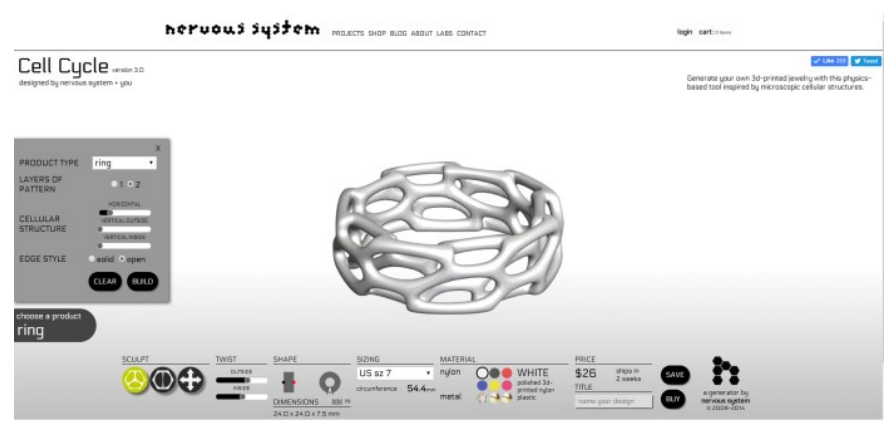


Figure 2. Screenshot of the Nervous System Cell Cycle customisation webpage

\subsection{Sample}

In total, 15 participants took part in the study. They were assigned one of the two websites and directed to customise a specific pre-selected product. In the end, 7 participants tried the Adidas site and 8 used Nervous System. Inclusion of new participants was stopped when no new opinions appeared.

Among the participants, 6 are male and 9 are female. 6 participants are aged 18-24 and 9 participants belong to the 25-34 age group. Regarding their educational background, 8 participants had already gained a master's degree, 4 of them had achieved a bachelor's degree and the remaining 3 participants were undergraduate students. Only 3 participants had previously shopped on mass customisation websites before the study. In comparison, the majority of participants $(n=12)$ had not spent any money on purchases using a mass customisation website.

\subsection{Analysis}

The interviews were recorded and transcribed. Given the exploratory nature of this research, an inductive coding method was employed to investigate participants' experience of customising a product and their purchase intention of the product they customised. After the transcripts were coded, the codes were analysed and sorted into categories.

Data gathered from post-interview questionnaires were also analysed. The results were compared with interview results to investigate if participants' experience was related to their demographic information.

\section{RESULTS}

The results of the data analysis have identified, among the various categories, six factors that are influential to consumer purchase intention: price, design freedom, website information quality, visual presentation of products, trust and individual differences. The frequencies of these factors have been mentioned by the 15 participants is indicated in Table 1. Comments that are representative and explicit to demonstrate participants experience are selected.

\subsection{Design freedom}

All the interviewees $(n=15)$ mentioned that they were excited about the idea that they could design a product and have it made and delivered specially for them. Typical comments included:

"It is very interesting to play with all the options and design the ring. It is different from normal online shopping websites." - Participant 05

"I think it is great fun that you can design a product according to your preference rather than select a ready-made one from a long list." Participant 12
Table 1. Frequencies of participants commenting on the six factors

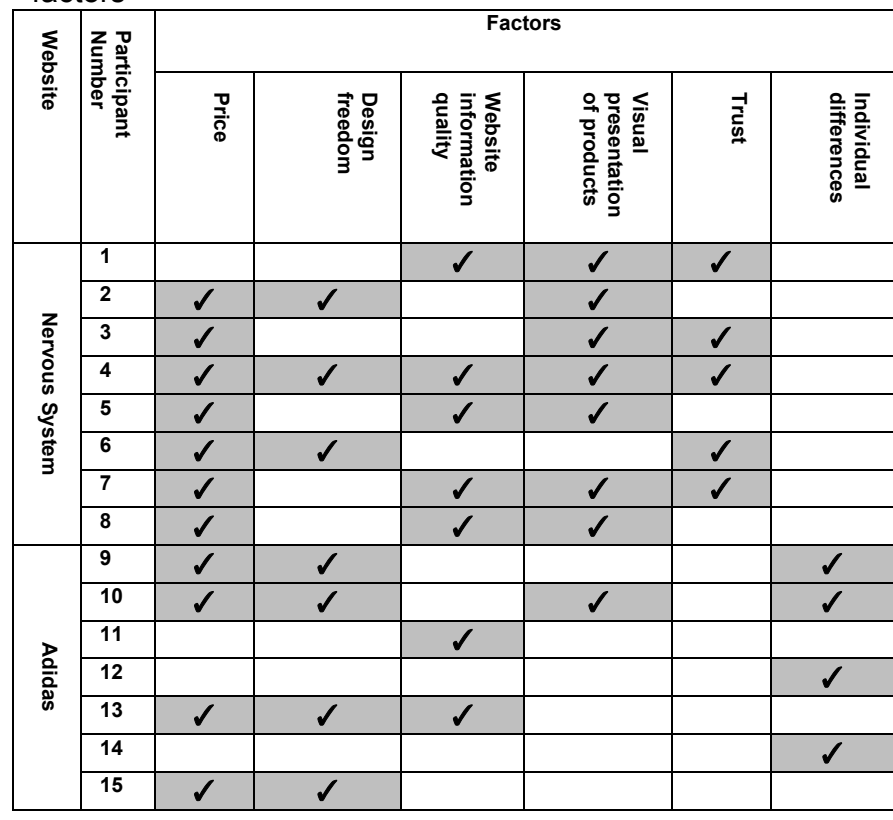

However, some interviewees $(n=9)$ felt frustrated that the options provided by these two websites were limited. This is especially the case for participants who used Adidas $(n=6)$. Some of them complained that they could not find the unique colour they wanted. This also led to their dissatisfaction with the customisation experience and they claimed that the final product failed to meet their expectation. Typical comments included:

"(Adidas) The choice of colour is very limited. Despite the variety of all the shoes, your choice of colour is between the choice of 5 or 6 colours. I don't understand why you can't have colour pick and just change it... if you think about it, say 7 people customise the same shoe, because it is such limited choices, in the end it doesn't feel personal." - Participant 10

"(Nervous System) I would like to have more choices to make further changes to the design, for example, putting my name on the ring. I also think there should be a choice that the circle hole can be replaced by other patterns, for example heart or square pattern."-Participant06

In addition to the number of choices, the approach of customisation also made a difference to participants' perceived design freedom. Participants were more satisfied with the customisation experience offered by Nervous System that they could change the shape of the product. Most participants $(n=5)$ agreed that the final product met their expectation. A few participants $(n=3)$ especially mentioned that the website offered tools which could change the physical structure of the product.

"I bought a laptop from a website that you can choose different components from a list, but this website provides you with tools that you can change the shape of the product and see the 
effect immediately, it is very different experience." -Participant 03

\subsection{Price}

When asked if they would like to purchase the product they customised, only two interviewees from the 15 said they would. The majority of the remainder $(n=13)$ gave price as their primary concern, especially those that were using the Nervous System site. Comments included:

"I would not buy this bangle at that price." Participant 04

Although price seemed the most frequently mentioned answer for not purchasing their designed product, surprisingly when asked if they can accept to pay a premium price for the customised product, only one interviewee believed that a mass customised product should be as cheap as or even cheaper than a mass produced product. All other participants said they were happy to pay a higher price for the customised products. The price premium they said they would be willing to pay ranged from $10 \%$ to $30 \%$. Nevertheless, participants also commented that the price premium they were willing to pay to some extent was dependent on how satisfied they were with the final product.

"The price is ridiculous...to be honest, I think it should be cheaper than mass produced products because it only creates the product when someone needs it so it should be cheap because you do not waste any material if you just make it for that one person." -Participant 05

"It is difficult to say (how much more I would like to pay for the customised product)...I guess it depends on how desperate I want it. If I really like my design and it is very unique, I would like to pay more for it." - Participant 14

\subsection{Website information quality}

All the participants pointed out that the customisation tools on the Nervous System website were not intuitive to use and there was not enough information to explain what each tool was and how it could change the product. They had to spend time to figure this out for themselves. In the end, a few participants could not figure out the functionality of the three main tools until the researcher told them in the interview. This was also given as an influential factor for why they did not wish to purchase the final product:

"I am still not entirely sure, this, the green one (button), I don't know what's that about." Participant04

"The buttons are not intuitive. I don't know what they can do if I just see them. Only after I click them I understand."-Participant07

"The final product is very expensive, so I would like to know all the buttons and then spent time designing the product. But if I did not know what the button can do, I would not want to buy the product in case I missed something." Participant 08

\subsection{Visual presentation of products}

The two websites selected in this study visualise products in a 3D interactive approach, which provides participants with the possibility of moving, rotating and zooming in/out. Nervous System allows consumers to rotate to see a full picture of the product. Adidas also allows rotations but with a fixed set of viewing angles.

Participants' comments confirmed the necessity of 3D visualisation of customisable products. They also would like to have the ultimate freedom of interacting with the 3D model, and they were frustrated if the website could not meet their expectation. Typical comments:

(Adidas) I don't mind having a 360 view in the end so I can actually see the entire shoe. If you go through, the view indeed changes depending on what you are editing. But I just expect to see the whole thing. It is a lot of money not knowing what to expect to turn up on the doorstep......Mass customization is a great idea, but you cannot go into the shop, you cannot try them on, you cannot decide oh actually they look really nice. So I think at least 360 view provides more variations of angles. - Participant 14

The potential downside of $3 D$ visualization is it consumes a large amount of internet resources, which may result in a slow response to participants' interaction. From the interviews, participants were sensitive to the website response speed, either quickly or slowly, which led to different feedback.

The website responded very quickly, and also the visualisation of the product is very good. You can immediately see the effects of modifying the product. For example, some websites just give you a picture, when you design a product, you cannot see how the changes you made actually influence the product immediately, but you can get real time feedback from this website. So I would say it is the real time interaction. Participant 08

Overall I am impressed with how quick it was, how easy it was. If I said show me white laces, it was very quick to do so. - Participant 12

Interestingly, when compared with the results of demographic questionnaires we also found that participants' comments on 3D visualisation are closely related to the average time they spend on computers and their previous experience of $3 \mathrm{D}$ software. Participants who spent longer time on computers or who used 3D software before, e.g. Maya, showed a more positive attitude towards the 3D visualisation, even if some of them had difficulties figuring out how to interact with the 3D product in the first place. In particular, one participant was a 3D modelling artist. He suggested 
improving the interactive experience by offering ultimate design freedom to consumers.

'I was also thinking if there would ever be kind of sketch-based option for me to do the sketch instead of just making choices...... So if you have this kind of, even just wireframe at first, and then you have some points, control points, like what we have in Maya or other 3D modelling software, it could stretch or squash one side or another, or even select this part to stretch or squash, to be more intuitive than just using slides to tilt. I don't know what is the tilting point when it starts tilting and in which direction. It is very very confusing or boring for me. It is kind of limited for my taste, I think. ' - Participant 04

\subsection{Trust}

Trust was also found to be an important influence on consumer purchase intention. This was especially true for Nervous System, which the participants had not encountered before the interviews. Five participants who used the Nervous System website indicated that lack of trust was one of the justifications for not wishing to purchase the final product they designed on the website. To further specify the reasons why they did not trust this website answers varied, including the website did not offer a free refund and the website did not use a secure https website connection:

"Nervous System, I don't like the name, of course I will be nervous if I spend that much money on a website I've never heard about." -Participant 04

"If I could free refund my order, I will buy it. I hope the refund process is not too complicated."Participant06

"I usually shop on websites with a 'secure' label in front of their (IP) address. I think the website with a secure label means it has been verified, I feel safe to shop on it."-Participant07

\subsection{Individual differences}

We also found from the results of the user study that the reasons for not willing to pay for the product participants designed on the Adidas site were somehow related to participants' individual differences, especially their personal preferences. For example, some participants did "not care about shoes" or "not like the brand" or "cannot find the colour they want". Nevertheless, we did not find that these individual preferences were related to their demographic information. Typical comments included:

"I am not really a shoe person... I don't care about the price because I know I won't buy it"Participant 10

"This brand of shoes is not something I like, so I won't buy it" - Participant 14

"I like one type of shoes but there are not many colour options, so I have to choose a different shoe to design because it has more colours." Participant 09
"It is more expensive for the customised Adidas shoes, and the customisable choices are mainly colours, the style and the shape of the shoes are same to the mass produced ones. As I am not that type of person who cares about being personal or being unique, I think the mass produced ones are good enough for me." Participant 12

\section{DISCUSSION}

The aim of this paper is to find answers to the research question "what are the factors that influence customer decisions to buy mass customised products?". 15 participants were invited to design a product using one of the mass customisation websites we selected: Adidas and Nervous System. After this was completed, an interview was conducted and each participant filled in a demographic questionnaire. The previous section (section 4) summarised the research findings and results from the interviews. In this section, we will further discuss the results and draw conclusions on the factors that influence consumer purchase intention of online mass customised products.

\subsection{Price}

This study confirmed that, in consumers' minds, mass customisation adds value to the product, for which they are willing to pay a premium. However, when it comes to a specific product, consumers become very price sensitive. The majority of the participants in the user study attributed the reasons why they would not buy customised products to the high price. Price has become one of the most important considerations that influence consumer purchase intention. This may be because the participants in this study are mainly young university students. Although they are the main consumer group for online shopping, they are not affluent with a high level of disposable income. A few participants mentioned that the reason they chose online shopping was because it is cheaper and it is easier to compare prices online.

However, this does not mean we should not consider young students as potential consumers. In the interview, three participants mentioned that they had purchased mass customised products before, but usually for special occasions or as a gift to friends or family. This indicates that there are still motivations and opportunities for young students to buy customised products.

In addition, from this study we can see that consumer purchase intention is influenced by multiple factors and price is not the only concern. When other factors (e.g., limited options, lack of trust, poor website design) do not meet consumer expectation, price becomes an obvious point to 'blame' for not buying the product. In this case, improving the consumer customisation experience will help to increase their purchase intention.

\subsection{Website design}

Previous studies have already found that website design plays an important role in consumer willingness to pay for online mass customisation [6]. This study 
explored further and suggests that website information quality and the visual presentation of products are two main factors that influence consumer purchase intention.

The results of the user study indicate that a number of mass customisation websites fail to provide consumers with essential information, especially information related to customising a product: what are the customisation options and how these options can change the design of products? This is particularly true for websites which options are organised by tools (e.g. Nervous System) rather than being directly displayed on the interface (e.g. Adidas). In this case, the interaction is more complicated so it is crucial to provide consumers with clear and sufficient information.

Considering a few participants commented on the importance of intuitive design, it is useful to display information on the website in an intuitive way, for example, through visualising the effect of customisation options. This is easy to achieve for some options, for example, the colour, while it requires more consideration for other options, for example, the size of the product. The websites we used in the user study employ numbers to demonstrate the changes of product size, for example, consumers can choose between $10 \mathrm{~cm}$ and $20 \mathrm{~cm}$. A problem of this approach is that it is not intuitive for consumers to understand the differences between the choices as numbers are abstract. One possible solution is allowing consumers to input their personal information e.g. height and weight and upload photos to the website, so that they can position the customised product over their photos according to a certain proportion and see if the size is appropriate for them. 3D laser scanning technologies also facilitate this process by capturing a physical object's exact size and shape and generating a digital $3 \mathrm{D}$ representation. This procedure can be applied before the payment, so that consumers can see the effect of the final product in a virtual environment. This could be especially important for customising personal products, e.g. jewellery, clothes.

Results of the user study also indicated that the majority of the participants were positive about the 3D presentation of customisable products and agreed that a $3 D$ visualisation helped them gain a full view of the product. Previous studies defined this type of online shopping as a virtual experience which is mediated by a 3D product environment [33] [34]. The work [34] presents two types of control for virtual experience: visual control and function control. Visual control allows consumers to view the product from different angles and distances while function control allows consumers to activate different functions of the product. In this case, 3D visualisation of the product provides consumers with the possibilities of modifying the structure and functions of the product which offers consumers more design freedom. An approach to achieve this is that instead of a single specific product, a predefined design of a "parametric family" is introduced with an instance choice controlled by a set of parameters introduced by its designer, each with an allowed variation range. In this case, not only can the shape of the 3D product change, but also its topology such as the number of through holes or "handles" and other topological characteristics [14].

\subsection{Differences between new startup companies and well established companies}

Another important finding from the interviews is that participants responded differently to Adidas and Nervous System when explaining the reasons for not purchasing their customised final products. This indicated that consumers may have different expectations from well established companies and new startup companies when they are considering online mass customisation.

For Adidas, the most frequently mentioned reasons for not purchasing products on its website is high price, limited design options and different individual preferences, for example, some participants do not like the brand or do not care about shoes. For Nervous System, in addition to the price concern, lack of trust has become the second greatest concern together with poor website information quality. From the interview, we can see that participants held a suspicious attitude towards the Nervous System website - they had never heard of the company and they did not know if this website could be trusted from the information provided on the website.

Participants' different responses to Adidas and Nervous System also indicates that new companies which employ mass customisation from the beginning may need to apply different strategies when compared to companies that are already strongly established which wish to start using mass customisation. For example, in order for well-established companies to attract more consumers to engage with their customisation service, the key is to consider the speciality of their product, identify their target consumers and offer unique and personal options to meet consumer needs and desires. According to participants' comments, the customisable options on the Adidas website are mainly to change the colour and material of different parts of the shoes, and the colour options are common colours that are often used in their mass produced shoes. This does not appear to meet consumer expectation of having truly unique colour choices. In this case, it was suggested by a participant (Participant 10) that a much broader colour palette can be used to allow consumers to choose whichever colour they want. This will give consumers unlimited freedom, though it may lead to inefficiency and difficulty from a manufacturing perspective. Further, it may also be a good idea to consider the speciality of their products. Allowing consumers to type in the measurements of their feet and produce a pair of shoes that exactly fits the shape of their feet may help them to gain a sense of uniqueness, which therefore adds value to the product. In the end, since an attribute-based approach (e.g. the approach Nervous System employs) seems to gain more positive feedback from the participants than the alternative-based approach, well established companies may also consider adding more 'fun' interaction mechanisms to their website and 
customisation process rather than just allowing consumers to click buttons.

For new startup companies, according to the results of the user study, it is important for these companies to build trust with their website visitors and consumers. An effective way to increase consumer trust is to provide excellent customer service. For example, when consumers have problems to interact with the website, it would be good if the consumer could be connected to customer service and gain real-time help through online chat or a telephone call. On one hand, this will help consumers solve the problem and avoid their frustration of using the website, while on the other hand it helps to build trust between consumers and companies because consumers can feel that the company cares about them. In addition to customer service, we can see from the interview that the guarantee of free return and refund will also help to boost consumer confidence with the website, therefore increasing their purchase intention.

In the end, the user study showed that a few participants who complained the website failed to provide essential information also commented on their lack of trust in the website. Previous studies [35] concluded that a high quality website helps build consumer trust towards the company. This study further indicated that this principle extends to mass customisation websites and that the information quality of a website particularly influences consumer perception of trust. This is extremely important for startup companies because the website is the primary means that consumers get to know the company. In the interview, the majority of participants complained that the Nervous System website failed to provide enough information for them to understand how to customise the product, which influenced their decision of purchase. Previous studies [13-15] provide useful suggestions on the design of mass customisation websites, which can be a reference for start-up companies.

\section{CONCLUSIONS AND LIMITATIONS}

This research aims to explore the reasons why consumers do not buy online mass customised products. To achieve this, we took an explorative approach through learning about participants' experience of customising a product on two selected websites. The results of the user study contribute towards three important findings: first, this study identifies six factors that can have an influence on consumer purchase intention of online mass customised products: price, design freedom, website information quality, visual presentation of the products, trust and individual differences. This study agreed with previous studies that price is an important concern when consumers make decisions to purchase mass customised products, no matter what website they use and their personal background. Second, mass customisation website design plays a significant role in helping consumers make purchase decisions, specifically, depending on two dimensions: website information quality and $3 D$ visual presentation of customisable products. Consumers are more likely to buy products from a website which has clear and sufficient information and provides a $3 D$ view of the product. Third, this study found that consumers' purchase intention is influenced by different factors between new start companies and well-established companies. In addition to price as a shared justification, for new companies lack of trust is an important reason that prevents consumers buying online; while for well established companies, it is important to target consumers' individual preferences and unique needs are key considerations.

One of the biggest limitations of this study is the small number of participants $(n=15)$. A small sample size limits the ability to generalise the findings of the present research. However, as a pilot study, the obtained results help us to gain an insight into the field and provide possible new answers to research questions. Further studies are needed to test the findings of this study on a larger scale. In addition, the participants are mainly academic staff and students, which do not represent a whole population. Therefore, two further studies are planned in future: first, more interviews will be carried out with participants from a more diverse background. Second, based on the results of the two interviews, a questionnaire will be designed and distributed to a larger number of participants.

\section{ACKNOWLEDGEMENT}

This work was funded by the European Commission Horizon 2020 - Marie Curie Individual Fellowship [grant number 661501].

\section{REFERENCES}

[1] Bardakci, A. and Whitelock, J. (2004), "How "ready" are customers for mass customisation? An exploratory investigation", European Journal of Marketing, Vol. 38, No. 11/12, pp.1396-1416.

[2] Moon, J., Chadee, D. and Tikoo, S. (2008), "Culture, product type, and price influences on consumer purchase intention to buy personalized products online", Journal of Business Research, Vol. 61, No. 1, pp. 31-9.

[3] Jiang, P., Balasubramanian, S.K. and Lambert Z.V. (2015), "Responses to customized products: the consumers' behavioral intentions", Journal of Services Marketing, Vol. 29, No. 4, pp.314326.

[4] Simonson, I. (2005), "Determinants of customers' responses to customized offers: Conceptual framework and research propositions", Journal of Marketing, Vol. 61, No. 1, pp.32-45.

[5] Broekhuizen, T.L.J. and Alsem, K.J. (2002), "Success factors for mass customization: a conceptual model", Journal of MarketFocused Management, Vol. 5, No. 4, pp.309-330.

[6] Trentin, A., Perin, E. and Forza, C. (2014), "Increasing the consumer-perceived benefits of a mass-customization experience through sales-configurator capabilities", Computers in Industry, Vol. 65, No. 4, pp.693-705.

[7] Franke, N., Schreier, M. and Kaiser, U. (2010), "The 'I designed it myself' effect in mass customization", Management science, Vol. 56, No. 1, pp.125-140.

[8] Khan, A. and Haasis, H.D. (2016), "Producer-buyer interaction under mass customization: analysis through automotive industry", Logistics Research, Vol. 9, No. 1, p.17.

[9] Hart, C.W. (1995), "Mass customization: conceptual underpinnings, opportunities and limits", International Journal of Service Industry Management, Vol. 6, No. 2, pp.36-45.

[10] Johnson, C. and Tesch, B. (2006), "Who buys custom consumer products?", Cambridge, MA: Forrester Research.

[11] Rose, S., Clark, M., Samouel, P. and Hair, N. (2012), "Online customer experience in e-retailing: an empirical model of 
antecedents and outcomes", Journal of Retailing, Vol. 88, No. 2, pp.308-322.

[12] Trentin, A., Perin, E. and Forza, C. (2013), "Sales configurator capabilities to avoid the product variety paradox: Construct development and validation", Computers in Industry, Vol. 64, No. 4, pp.436-447.

[13] von Hippel, E. (2001), "User toolkits for innovation", Journal of Product Innovation Management, Vol. 18, No. 4, pp. 247-257.

[14] Zhao, H., McLoughlin, L., Adzhiev, V. and Pasko, A. (2019), "3D Mass Customization Toolkits Design, Part I: Survey and an Evaluation Model", Computer-Aided Design \& Applications, Vol. 16, No. 2, pp. 204-222.

[15] Piller, F. (2012), "The MC Graveyard: Ideas that did not make it: Kidlandia strikes colors", available at: http://masscustomization.blogs.com/mass_customization_open_i/2012/11/th e-mc-graveyard-ideas-that-did-not-make-it-kidlandia-strikescolors.html

[16] Gandhi, A., Magar, C. and Roberts, R. (2014), "How technology can drive the next wave of mass customization", Business Technology Office, pp.1-8.

[17] Wikström, S. (1996), "Value creation by company-consumer interaction", Journal of Marketing Management, Vol. 12, No. 5, pp. 359-374.

[18] Khalid, H. M. and Oon, Y. B. (2003), "Usability of configuration systems in design by customer web sites", in Proceedings of the Human Factors and Ergonomics Society Annual Meeting, Vol. 47, No. 5 , pp. 811-815.

[19] Franke, N. and Piller, F. (2003), "Toolkits of User Innovation and Design: an Exploration of User Interaction and Value Creation in the Watch Market", in Proceedings of the 2nd Interdisciplinary World Congress on Mass Customization and Personalization.

[20] Franke, N. and Piller, F. (2003), "Key research issues in user interaction with user toolkits in a mass customisation system", International Journal of Technology Management, Vol. 26, No. 56, pp.578-599.

[21] Matzler, K. Stieger, D. and Füller, J. (2011), "Consumer confusion in internet-based mass customization: Testing a network of antecedents and consequences", Journal of Consumer Policy, Vol. 34, No. 2, pp.231-247.

[22] Huffman, C. and Kahn, B. E. (1998), "Variety for sale: Mass customization or mass confusion?", Journal of Retailing, Vol. 74, No. 4, pp. 491-513.

[23] Kamis, A., Koufaris, M. and Stern, T. (2008), "Using an attributebased decision support system for user-customized products online: an experimental investigation", Mls Quarterly, pp.159-177.

[24] Valenzuela, A., Dhar, R. and Zettelmeyer, F. (2009), "Contingent response to self-customization procedures: Implications for decision satisfaction and choice", Journal of Marketing Research, Vol. 46, No. 6, pp. 754-763.

[25] Hermans, G. (2012), "A model for evaluating the solution space of mass customization toolkits", International Journal of Industrial Engineering and Management, Vol. 3, No. 4, pp. 205- 214.

[26] Davis, S. M. (1987), Future perfect, New York, USA: AddisonWesley Publishing Company.

[27] Davis. S. M. (1989), "From 'future perfect': Mass customizing", Planning Review, Vol. 17, No. 2, pp. 16-21.

[28] Pine, B. J. (1993), Mass Customization: The New Frontier in Business Competition, Harvard Business Press.

[29] Tseng, M. M. and Jiao, J. (2001), Mass Customization in Handbook of Industrial Engineering, Technology and Operation Management, Wiley.

[30] Sandrin, E., Trentin, A., Grosso C. and Forza, C. (2017) "Enhancing the consumer-perceived benefits of a masscustomized product through its online sales configurator: an empirical examination", Industrial Management \& Data Systems, Vol. 117 , No. 6, pp. 1295-1315.'

[31] Sandrin, E. (2017), "Synergic effects of sales-configurator capabilities on consumer-perceived benefits of mass-customized products", International Journal of Industrial Engineering and Management, Vol. 8, No. 3, pp. 177-188.

[32] Merle, A., Chandon, J.-L., Roux, E. and Alizon, F. (2010), "Perceived value of the mass-customized product and mass customization experience for individual consumers", Production and Operations Management, Vol. 19, No. 5, pp. 503-514.

[33] Li, H., Daugherty, T. and Biocca, F. (2001), "Characteristics of virtual experience in electronic commerce: A protocol analysis", Journal of Interactive Marketing, Vol. 15, No. 3, pp. 13-30.
[34] Jiang, Z. and Benbasat, I. (2004), "Virtual product experience: Effects of visual and functional control of products on perceived diagnosticity and flow in electronic shopping", Journal of Management Information Systems, Vol. 21, No. 3, pp.111-147.

[35] Wang, Y. D. and Emurian, H. H. (2005). "Trust in e-commerce: consideration of interface design factors", Journal of Electronic Commerce in Organizations, Vol. 3, No. 4, pp. 42-60.

[ii] https://rctom.hbs.org/submission/nikeid-polishing-the-shoe-buyingexperiencel

[iii] https://rctom.hbs.org/submission/nikeid-polishing-the-shoe-buyingexperience/

[iv]https://www2.deloitte.com/content/dam/Deloitte/ch/Documents/cons umer-business/ch-en-consumer-business-made-to-order-consumerreview.pdf

$\left.{ }^{[v}\right]_{\text {https://www2.deloitte.com/uk/en/pages/press-releases/articles/one- }}$ in-three-consumers-wants-personalised-products.html

[vi] http://ec.europa.eu/eurostat/statistics-explained/index.php/Ecommerce_statistics_for_individuals\#General_overview

[vii] https://www2.deloitte.com/uk/en/pages/pressreleases/articles/one-in-three-consumers-wants-personalisedproducts.html 